\title{
Validation of the acaricidal properties of materials used in ethno-veterinary control of cattle ticks
}

\author{
Busani Moyo ${ }^{1 *}$ and Patrick Julius Masika ${ }^{2 \star}$ \\ ${ }^{1}$ Department of Livestock and Pasture Sciences, Faculty of Science and Agriculture, University of Fort Hare, P/Bag X \\ 1314, Alice 5700. South Africa. \\ ${ }^{2}$ Agriculture and Rural Development Research Institute, Faculty of Science and Agriculture, University of Fort Hare, \\ P/Bag X 1314, Alice 5700. South Africa.
}

Accepted 26 July, 2013

\begin{abstract}
Ticks are vectors of tick-borne diseases, cause teat damage and tick-worry. They are commonly controlled using conventional acaricides, which are expensive to the resource-limited farmers, making them to resort to alternative tick control materials. The objective of this study was to validate the acaricidal properties of various ethno-veterinary materials used by rural farmers in the Eastern Cape Province of South Africa. In vitro repellency and contact bio-assay models were carried out to determine the repellency and acaricidal properties of Ptaeroxylon obliquum, Aloe ferox Mill, Lantana camara L, Tagetes minuta, used engine oil and Jeyes fluid on Rhipicephalus sanguineus ticks. The optimum repellency of Jeyes fluid at concentrations of 76.8 and $100 \%$ lasted for 6 and $7 \mathrm{~h}$, respectively. Tabard the reference product lasted for $4 \mathrm{~h}$. P. obliquum $(\mathbf{4 0} \%)$ repelled the ticks for $\mathbf{4 0}$ min. For the contact bio-assay, used engine oil, T. minuta oil $(50 \%)$, Ektoban ${ }^{\circledR}$ and Jeyes fluid $(76.8 \%)$ caused tick mortality of more than $86 \%$. This study reveals that the materials rural farmers use to control ticks vary in their efficacy. Jeyes fluid and used engine oil have acaricidal effect as the conventional acaricides whereas extracts of $A$. ferox, $L$. camara and $T$. minuta are not.
\end{abstract}

Key words: Acaricides, ethno-veterinary materials, repellency, Rhipicephalus sanguineus

\section{INTRODUCTION}

Ticks are one of the major factors that contribute to animal health problems and exert the greatest limitation in cattle production, by causing serious debility, morbidity, mortality and production losses in cattle (Okello-Onen et al., 2004; Moyo and Masika, 2009). They also transmit pathogens such as Anaplasma spp., Babesia spp., Theileria spp. and Ehrlichia species (Bram, 1983; L'Hostis and Seegers, 2002). The common tick species in the Eastern Cape Province of South Africa are Rhipicephalus appendiculatus, Rhipicephalus evertsi evertsi, Rhipicephalus (Boophilus) decoloratus and Rhipicephalus sanguineus (Marufu et al., 2010).

Ticks are commonly controlled using conventional aca- ricides which are applied as dips or sprays and pour-on at various frequencies. Some of the conventional acaricides have repellency or acaricidial properties. Use of repellent acaricides for animal protection against ticks, constitute an important prophylactic component of tickborne disease (TBD) management strategy (Dautel, 2004). Same applies to the contact acaricides which are chemical agents meant to kill ticks and are largely toxic through contact action (Boden and West, 1998). Some of the acaricides have long residual effect while others degrade rapidly after application (Brimecombe, 2006). Unfortunately, these chemicals are expensive, not readily available to the resources-limited farmers. In addition, the 
undegradable residues contained in conventional acaricides may pollute the products (milk and meat) and the environment, and ticks have developed resistance to them (Okello-Onen and Rutagwenda, 1997). This has caused farmers to turn to low cost alternatives such as ethno-veterinary materials namely used engine oil, Jeyes fluid, Aloe ferox Mill and Ptaeroxylon obliquum (Moyo and Masika, 2009; Moyo et al., 2009).

The alternative materials like used engine oil are highly complex mixture, containing compounds distilled from petroleum, for example aliphatic hydrocarbons, aromatic hydrocarbons, polycyclic aromatic hydrocarbons [PAHs]), as well as metals such as aluminium, chromium, lead, manganese (Delistraty and Stone, 2007). Also, the Jeyes fluid a commercial disinfectant which is registered for use on non-living materials contains carbolic acid $13 \% \mathrm{~m} / \mathrm{m}$ identified as phenol $(6 \mathrm{H} 5 \mathrm{OH})$ and sodium hydroxide $(1 \%)$ (Chem. Alert Report, 2005). However, some of these alternatives like Jeyes fluid and used engine oil are equal or more toxic than the conventional acaricides and are not the best option to be used in tick control in livestock (Aitken and Barrett, 2007; Delistraty and Stone, 2007).

In Zimbabwe for example, ethno-veterinary medicine is gaining recognition at the expense of conventional drugs especially because of its greater accessibility, lower costs and apparent effectiveness (Mwale et al., 2005) and little work on validation have been done. Many small-scale farmers are known to use ethno-veterinary practices for the control of ticks (Njoroge and Bussmann, 2006).

The purpose of this study was to validate the acaricidal properties of $P$. obliquum, Aloe ferox, Lantana camara, Tagetes minuta, used engine oil and Jeyes fluid on $R$. sanguineus ticks.

\section{MATERIALS AND METHODS}

\section{Plant material collection}

The leaves of $A$. ferox Mill, Voucher number BM01-037/2007, $L$. camara L Voucher No. BM01-039/2007, T. minuta L Voucher No. BM01-040/2007 and the bark of $P$. obliquum (Thunb) Radlk Voucher No. BM01-038/2007 were collected before flowering within Amathole District Muncipality $\left(30^{\circ} 15^{\prime} 15^{\prime \prime} \mathrm{S}\right.$ and $\left.22^{\circ} 15^{\prime} 36^{\prime \prime} \mathrm{E}\right)$, South Africa.

\section{Preparation of the plant materials}

\section{Aqueous extraction of dried plant material}

Fresh plant material (leaves of $L$. camara, T. minuta, A. ferox and the fresh bark of $P$. obliquum) were collected, air dried under shade for six weeks and then milled into powder using a hammer mill with $1 \mathrm{~mm}$ pore size sieve according to the farmers' description. $100 \mathrm{~g}$ of the respective plant materials were mixed with $1000 \mathrm{ml}$ of distilled water and soaked overnight. The extracts were filtered using Whatman No.1 filter paper. The filtrate was then lyophilized using a freeze drying system Xerotec (model Cd 052, Kenmore international, Italy) for $72 \mathrm{~h}$, yielding $10,9,11$ and $12 \mathrm{~g}$ of extracts of $L$. camara, $T$. minuta, A. ferox and $P$. obliquum, respectively. The resulting extracts was stored in capped bottles and kept in the refri- gerator until use. The extracts were reconstituted using distilled water to make different concentrations of 10,20 and $30 \%(\mathrm{w} / \mathrm{v})$.

\section{Aqueous extraction of fresh plant material}

Fresh leaves of $L$. camara, $T$. minuta and $A$. ferox and the fresh bark of $P$. obliquum were collected and thoroughly washed using distilled water. Plant material of 40,60 and $80 \mathrm{~g}$ were placed in 200 $\mathrm{ml}$ of distilled water and macerated for 1 min using an electric Sunbeam Deluxe glass blender model SGB-150, Johannesburg, South Africa.

Generally, the farmers crush the plant materials using mortar and pestle. The mixture was stored at room temperature overnight and later strained using a muslin cloth. The concentration percentages of extracts were determined using weight per volume (Jayasinghe, $1975)$ to obtain a 20,30 and $40 \%(\mathrm{w} / \mathrm{v})$ extract. The plant extracts were prepared as per information given by the farmers (Moyo and Masika, 2009)

\section{Extraction of oil}

Quantities $(200 \mathrm{~g})$ of leaves for L. camara, A. ferox, T. minuta and the bark of $P$. obliquum were mixed with $5 \mathrm{~L}$ of distilled water separately subjected to hydro distillation for $3 \mathrm{~h}$ using a clevengertype apparatus (Soffiera vetro, Sassari, Italy). With the exception of $T$. minuta, the others yielded negligible quantities of oil. The Tagetes oil was diluted to concentrations of $3.125,6.25,12.5,25$, 50 and $100 \%$ using olive oil, to find out which concentration has the acaricidal activity.

\section{Extraction of aloe leaf exudates}

The aloe leaf exudates were obtained by cutting the aloe leaves and the exudates was collected, air dried and stored in bottles. It was reconstituted to the following concentrations: 1.8, 3.5, 7.5 and $15 \%$ using distilled water. Different extraction methods and concentrations of materials were used to assist in the screening of materials having acaricidal properties.

\section{Preparation of non-plant materials}

Jeyes fluid (Adcock Ingram, Bryanston, South Africa), a household disinfectant was diluted using distilled water to make the following concentrations: $0.6,1.2,2.4,4.8,9.6,19.2,38.4,76.8$ and $100 \%$. Used engine oil was used undiluted. A commercial acaricides, Ektoban ${ }^{\circledR}$ (cymiazol $17.5 \% \mathrm{w} / \mathrm{v}$ and cypermethrin $2.5 \% \mathrm{w} / \mathrm{v}$ Novartis, Johannesburg, South Africa) registered for the control of ticks (Swan, 2001) was also used. A standard insect repellent material, Tabard (35\% diethyloluamide, Acorn (Pty) Ltd, strubens Valley, South Africa) which is effective against fleas, ticks, flies and gnats (Acorn South Africa (Pty) Ltd, 2009, personal communication) was used as a positive control.

\section{Ticks}

Adult and nymph stages of $R$. sanguineus were obtained from Clinvet International, Bloemfontein, South Africa. This tick species was selected for the study because it affects both cattle and dogs. In addition, it was the only tick species that was cultured having same age and from the same environment. The ticks were held in small transport vials supported with moist Whatman filter paper and fresh green grass. They were kept at $75 \%$ relative humidity and a temperature of $25 \pm 1^{\circ} \mathrm{C}$, to produce an environment conducive for the survival of ticks (Thorsell et al., 2005). 


\section{In vitro repellency bioassay}

The repellency method described by Thorsell et al. (2005) was used in this bioassay. The nymphal stage of $R$. sanguineus tick species was used to test the repellency properties of ethnoveterinary materials (Chungsamarnyart et al., 2003). Two filter papers (Whatman No. 1) were placed inside a Petri-dish with an inner diameter of $9.5 \mathrm{~cm}$. Tabard (diethyltoluamide $350 \mathrm{mg}$ ) an insect repellent was used as positive control while distilled water was used as negative control. Aliquots of $0.5 \mathrm{ml}$ of the test solutions were applied along the periphery of the filter papers. The filter papers were then air dried for 2 min. Each test was replicated three times.

Six nymphs were placed at the centre of each of the treated filter papers and their movement with regards to avoiding the treated area was observed. If the nymph continued its motion beyond the periphery of the treated area within $5 \mathrm{~min}$, the tick was indicated as non-repelled; conversely, if the nymph reversed its direction before reaching the periphery of the treated area the tick was considered as repelled. The Petri dishes were uncovered and exposed to the air from the start to the end of the experiment. The test was repeated after $0.33,0.67,1,2,3,4,5,6,7,8$ and $9 \mathrm{~h}$ after treatment. At each occasion, the number of nymphs avoiding the treated area was recorded. The repellency was expressed as number of nymphs avoiding treated area to the total number of nymphs at each occasion. Thus, 6 nymphs avoiding the treated area out of a total of 6 is recorded as $100 \%$ repellency. The repellency was calculated according to Thorsell et al. (2005) as follows:

$$
R=\frac{a}{n} \times 100
$$

Where $\mathrm{R}$ is the repellency; $\mathrm{a}=$ the number of nymphs avoiding the treated area; and $n=$ the total number of nymphs put in the centre of filter paper at each occasion.

\section{Contact bioassay on ticks}

The dipping method was used for in vitro bioassay (PiraliKheirabadi et al., 2007). Adult $R$. sanguineus ticks were divided into groups of five and each group was immersed in a specific concentration of test samples ranging from 10, 15, 20, 30 to $40 \%$ for one minute. Distilled water and acaricide (Ektoban $\left.{ }^{\circledR}\right)$ were used as negative and positive control, respectively. After dipping in the respective materials, each group was placed into separate Petri dishes containing moist Whatman No. 1 filter papers measuring $62.63 \mathrm{~cm}^{2}$, with pieces of green grass to provide an environment conducive for tick survival (Thorsell et al., 2005). The tick samples were incubated for 7 days at $25^{\circ} \mathrm{C}$ and $75 \%$ relative humidity in the dark as described by Pirali-Kheirabadi et al. (2007) with slight modifications. Each treatment was replicated three times. The Petri dishes were examined on an hourly basis for the first $6 \mathrm{~h}$ after treatment, and thereafter every $24 \mathrm{~h}$ in the morning; to count and remove the dead ticks (Pamo et al., 2005). The tick mortality rate was calculated according to Abott (1925) and Chungsamarnyart et al. (2003) as follows:

Corrected mortality $(\%)=\left(1-\frac{T}{C}\right) \times 100$

Where: $T$ is the number of ticks remaining alive after treatment; $C$ is the number of ticks remaining alive in the control group.

Ticks were considered alive if they exhibited normal behavior (movement looking for the host) when breathed upon or physically stimulated with a wooden stick. For each time point, if ticks were incapable of moving, maintaining a normal posture, leg coordination, being upright themselves, or showing any sign of life, they were considered moribund or dead (Panella et al., 2005).

\section{Statistical analysis}

\section{In vitro repellency bioassay}

The percentage tick repellency was calculated according to Thorsell et al. (2005). Mean repellency for all materials used was calculated.

\section{Contact bio-assay}

The following model was used to analyze tick mortality caused by treatment materials.

$Y_{i j}=\mu+T_{i}+\varepsilon_{i j}$

Where $Y_{i j}=$ response effect (mortality) due to treatment; $\mu=$ overall mean (constant); $T_{i}=$ effect due to treatment $(1=1,2,3 \ldots$ and 32$)$; $E_{i j}=$ residual error .

The collected data was then analyzed using PROC GLM for repeated measures (SAS, 2003). P-values $<0.05$ were regarded as significant. Duncan test was used to compare differences between treatment means.

\section{RESULTS}

\section{In vitro repellency bioassay}

With the exception of $P$. obliquum, the other plant extracts did not show any tick repellency effect. Only $P$. obliquum (40\%) and Jeyes fluid (9.6 to $100 \%$ concentration) showed repellency as shown in Table 1. The repellency duration was shorter for $P$. obliquum (40 min) than Jeyes fluid $>9.6 \%(1-8 \mathrm{~h})$. The Jeyes fluid at 76.8 and $100 \%$ concentration was effective (repellent) for 7 and $8 \mathrm{~h}$, while the positive control, Tabard was effective for $4 \mathrm{~h}$ after application. Extracts of L. camara (20 and $40 \%$ ), A. ferox (20 and 40\%), T. minuta (20 and 40\%), T. minuta oil, used engine oil, olive oil and $A$. ferox leaf exudates $(1.8,3.5,7.5$ and $15 \%)$ showed no repellency The repellency of Jeyes fluid was effective from a concentration of 2.4 to $100 \%$.

\section{Contact bio-assay}

The plant extracts did not yield any acaricidal properties. Used engine oil, Ektoban $\AA$, T. minuta oil ( 25 and $50 \%$ ) and Jeyes fluid (19.2, 38.4, 76.8, and 100\%) showed variable acaricidal efficacy with the following mortalities: $93,87,13,100,26.7,66.7,86.6$ and $100 \%$, respectively within the first $24 \mathrm{~h}$ after application as shown in Table 2. A. ferox leaf exudates immobilized the ticks for the first $12 \mathrm{~h}$ and later they became active.

\section{DISCUSSION}

In all the experiments, it was clear that the nymphs displayed 
Table 1. Tick repelling activity of $P$. obliquum and Jeyes fluid at different concentrations.

\begin{tabular}{|c|c|c|c|c|c|c|c|c|c|c|c|}
\hline \multirow{2}{*}{ Material } & \multicolumn{11}{|c|}{ Tick repellency (\%) } \\
\hline & $20 \mathrm{~min}$ & $40 \mathrm{~min}$ & $1 \mathrm{~h}$ & $2 \mathrm{~h}$ & $3 \mathrm{~h}$ & $4 h$ & $5 \mathrm{~h}$ & $6 \mathrm{~h}$ & $7 \mathrm{~h}$ & $8 \mathrm{~h}$ & $9 \mathrm{~h}$ \\
\hline P. obliquum (40\%) & 100 & 94 & 0 & 0 & 0 & 0 & 0 & 0 & 0 & 0 & 0 \\
\hline Jeyes fluid $(9.6 \%)$ & 100 & 100 & 72 & 0 & 0 & 0 & 0 & 0 & 0 & 0 & 0 \\
\hline Jeyes fluid (19.2\%) & 100 & 100 & 100 & 94 & 22 & 0 & 0 & 0 & 0 & 0 & 0 \\
\hline Jeyes fluid (38.4\%) & 100 & 100 & 100 & 100 & 78 & 22 & 0 & 0 & 0 & 0 & 0 \\
\hline Jeyes fluid (76.8\%) & 100 & 100 & 100 & 100 & 100 & 100 & 100 & 89 & 33 & 0 & 0 \\
\hline Jeyes fluid (100\%) & 100 & 100 & 100 & 100 & 100 & 100 & 100 & 100 & 83 & 28 & 0 \\
\hline Tabard (35\%) & 100 & 100 & 100 & 100 & 100 & 94 & 56 & 6 & 0 & 0 & 0 \\
\hline
\end{tabular}

Table 2. Least square means for acaricidal effect of some ethno-veterinary remedies.

\begin{tabular}{|c|c|c|c|c|c|c|c|c|c|c|c|c|c|c|}
\hline \multirow{2}{*}{ Material } & \multicolumn{13}{|c|}{ Tick mortality (\%) } & \multirow{2}{*}{$\begin{array}{c}\text { Total tick } \\
\text { mortality (\%) }\end{array}$} \\
\hline & $1 \mathrm{~h}$ & $2 \mathrm{~h}$ & $3 \mathrm{~h}$ & $4 h$ & $5 \mathrm{~h}$ & $6 \mathrm{~h}$ & 1 day & 2 days & 3 days & 4 days & 5 days & 6 days & 7 days & \\
\hline Used engine oil & 73 & 0 & 0 & 13 & 7 & 0 & 93 & 0 & 0 & 0 & 0 & 0 & 7 & $100^{\mathrm{a}}$ \\
\hline T. minuta oil $(50 \%)$ & 60 & 40 & - & - & - & - & 100 & - & - & - & - & - & - & $100^{a}$ \\
\hline T. minuta oil (100\%) & 100 & - & - & - & - & - & 100 & - & - & - & - & - & - & $100^{\mathrm{a}}$ \\
\hline Jeyes fluid (38.4\%) & 6.7 & 60 & 0 & 0 & 0 & 0 & 66.7 & 0 & 0 & 0 & 0 & 0 & 0 & $66.7^{c}$ \\
\hline Jeyes fluid (76.8\%) & 73.7 & 13.3 & 0 & 0 & 0 & 0 & 86.6 & 0 & 0 & 0 & 0 & 0 & 0 & $86.6^{b}$ \\
\hline Jeyes fluid (100\%) & 100 & - & - & - & - & - & 100 & - & - & - & - & - & - & $100^{a}$ \\
\hline Ektoban & 87 & 0 & 0 & 0 & 0 & 0 & 87 & 13 & - & - & - & - & - & $100^{a}$ \\
\hline
\end{tabular}

${ }_{a, b, c}$ Means in the column with different superscript letters differ significantly, $p<0.05$.

their natural host-seeking behavior during the tests. They moved around the filter paper and even crossed the treated areas for the extracts that did not show repellency.

The extracts of $P$. obliquum at $40 \%$ concentration had a short-lasting protection that provided $94 \%$ repellency at $40 \mathrm{~min}$ post-application against the nymph. This short repellency period may not be adequate to protect livestock against ticks. Tabard stick, our positive control, provided greater than $94 \%$ repellency for $4 \mathrm{~h}$ which was greater than the repellency period of $P$. obliquum. The bark of $P$. obliquum has been reported to contain saptaeroxylon (an acid saponin), pyrogall, resins and an alkaloid (Archer and Reynolds, 2001) with resins reported to have repellency activities (Pontes et al., 2007).

It is speculated that the resin oil in the $P$. obliquum was in small quantities which made the repellency to last for a short period of time or it was volatile in nature making it to lose its repellency. Therefore, further research is necessary to find ways of improving the duration period of repellency. The results of the contact bioassay are in contrast with those of Archer and Reynolds (2001), who indicated that the powder of the bark added to water kills cattle ticks. The variation could be attributed to the tick species and the age of the tree from where the bark was collected and growth environment which can influence the amount of compounds in the plant. The results obtained in this study indicate that essential oil of $T$. minuta had no repellency properties, however, it differs from the studies of Nchu et al. (2012) which showed some tick repellency against Hyalomma rufipes. This could 
be attributed to differences in tick species used in the study.

Jeyes fluid showed some acaricidal efficacy both through contact and repellency in the study which compared well with the positive control, Ektoban $\AA$ acaricide. The active ingredient of Jeyes fluid (carbolic acid) was once used as carbolic dip to control ticks more than 50 years ago (Malesela, 2004). Moreover, the carbolic acid is poisonous to tissues especially when applied directly to muscle and nerves, causing paralysis to the nerves which later paralysis the heart (Henriette, 2008) hence death of organisms.

However, the veterinarians do not recommend its use because carbolic dip has very narrow safety margins (Malesela, 2004; Aitken and Barrett, 2007). Carbolic dip caused some poisoning to animals dipped (Linklater et al., 1982; Aitken and Barrett, 2007). Moreso, its exposure in the animal skin have pathological effect (Chem Alert Report, 2005). The above reasons could have contributed to its withdrawal from the list of registered acaricides. In addition, Jeyes fluid is toxic to aquatic organisms, it alters the water pH (Irwin et al., 1997).

Jeyes fluid is locally available in shops and farmers maintain that it was cheaper as compared to the conventional acaricides and also kill ticks as reported by Malesela (2004) and Moyo et al. (2009). The residual effect of Jeyes fluid to consumers is not known. Therefore, its use should be avoided or used with caution and more research needs to be done on its toxicity.

The efficacy of used engine oil through contact bioassay compared well with the positive control conventional registered, Ektoban $\AA$ acaricide in agreement with Moyo et al. (2009). This was in contrast with the field efficacy findings by Dreyer et al. (1998) where it had an average efficacy of $38.1 \%$. The variation could be due to tick species or the field condition. The high mortality caused by used engine oil is ascribed to its action as a physical acaricide clogging the spiracles and causing the tick to suffocate (Dreyer et al., 1998). Therefore, direct contact between the oil and the tick is necessary for effective result (mortality). Mbati et al. (2002) and Masika et al. (1997) have documented the wide use of used engine oil. However, no validation was done. The toxic components in it, could be the ones that caused the death of the ticks.

The disadvantage of using used engine oil is that it has toxic components such as lead chromium, copper and zinc which have residual effect on plant and animal tissue making them unsafe for human consumption as cited by Moyo and Masika (2009). Used engine oil can contaminate the environment and water bodies resulting in the death of aquatic and soil microbes (Delistraty and Stone, 2007). This aspect needs investigation since little/no work has been done in this regard. However, many farmers in the Eastern Cape Province depend on government pensions (Dreyer, 1997), they cannot afford to buy conventional acaricides as such, they resort to using used engine oil to control ticks on their cattle.
The efficacy of $T$. minuta oil was comparable to that of the reference conventional acaricide, Ektoban $\AA$, which is very effective against ticks. This makes $T$. minuta oil an alternative acaricide that can be used by farmers. However, the cost of the oil may be prohibitive too. The acaricidal effect could be attributed to the compound terpens contained in $T$. minuta oil, which has been reported to have aphicidal and insecticidal properties (Sarin, 2004; Seyoun et al., 2007; Tomova et al., 2005). The effect of this oil on ticks, in this study concurs with its efficacy on other insects. The recommended concentration of $T$. minuta oil to be used as an acaricide could be $50 \%$ level. This is more economic than the $100 \%$ concentration which uses more essential oil.

Use of boiled T. minuta leaves kill ticks (Njoroge and Bussmann, 2006), as such farmers in the study area could benefit from boiling the leaves which is cheaper than distilling oil from the plants. The other plant extracts exhibited variable results ranging from no effect to lower mortality. Therefore, they cannot be used as alternative acaricides in tick control.

The extracts of $L$. camara at $40 \%$ concentration had a tick mortality of $27 \%$, which was inadequate for reducing tick burdens in livestock. Our findings however are in contrast with Okello-Onen et al. (2004) and Moyo et al. (2009) where its efficacy was 96.6 and $58 \%$ for all the tick species, respectively. The difference in the observations could be due to difference in the environment where the plant was collected and age of the plant. This affects the chemical composition of the plant. Also, this variation could be ascribed to the fact that acaricidal efficacy depends on the tick species.

The results of this study have revealed that the materials rural farmers use as acaricides vary in their efficacy to control ticks. Jeyes fluid and used engine oil are as effective as the conventional acaricides whereas others are not effective at all. Jeyes fluid $(38.4,76.8$ and $100 \%)$, T. minuta oil (50\%) and used engine oil had the most acaricidal properties. However, they also need to be validated in in vivo experiments. Despite being effective, used engine oil and Jeyes fluid have potential toxic effects on animals and are also environmental contaminants.

\section{ACKNOWLEDGEMENTS}

The authors acknowledge the financial support from the National Research Foundation of South Africa. They also extend their thanks to ARDRI staff and the Department of Livestock and Pasture Sciences at the University of Fort Hare in South Africa for their support.

\section{REFERENCES}

Abott WS (1925). A method for computing the effectiveness of an insecticide. J. Econ. Entomol. 18:265-267. 
Aitken I, Barrett T (2007). Diseases of sheep, http://books.google.co.za/book?isbn= 140513143 .

Archer R, Reynold Y (2001). Ptaeroxylon obliquum_(Thunb) Radlk. South Africa.National Biodiversity institute. (http://bold.cf.ac.uk/Bot.DermFolder/ BotDermR/RUTA.html).

Boden E, West GP (1998). Black's veterinary Dictionary.19 ${ }^{\text {th }}$ edition. http://books.google.co.za/books?isbn=038921017x.

Bram RA (1983). Tick-borne livestock diseases and their vectors. 1. The global problem. Wild Anim. Rev. 36:1-5.

Brimecombe RD (2006). Voltametric analysis of pesticides and their degradation: A case study of amitraz and its degradants. M. Sc. Thesis, Rhodes University.

Chem Alert Report http://www.waiwhetu.co.nz/msds/jd/jeyes\%20fluid \%20(nz).pdf.

Chungsamarnyart $\mathrm{N}$, Jansawan $\mathrm{W}$, Tassanawat $\mathrm{T}$, Thiapayarak $\mathrm{T}$ (2003). Efficacy of herbal Acaricide;K U Natural Extocide against the Tick, Flea, Lice of dogs. $28^{\text {th }}$ World Congress of the World small animal veterinary Association (October 24-27, 2003, Bangkok, Thailand.

Dautel H (2004). Test systems for tick repellents. Int. J. Med. Microbiol. 293:suppl. 37:182-188.

Delistraty D, Stone A (2007). Dioxins, metals, and fish toxicity in ash residue from space heaters burning used motor oil. Chemosphere 68:907-914

Dreyer K (1997). Ocurrence and control of parasites on cattle in urban and peri-urban environments with specific reference to ticks. M.Sc. Thesis, University of Orange Free State.

Dreyer K, Fourie LJ, Kok DJ (1998). The efficacy of used engine oil against ticks on cattle. Ondersterpoort J. Vet. Res. 65:275-279.

Henriette K (2008). http://www.henriettesherbal.com-copyright 19952008 Henriette Kress.

Irwin RJ, Mouwerick MV, Stevens L, Seese MD Basham W (1997). Environmental contaminants enclyopedia. (http://www.fws.gov/caribbean/es/PDF/contaminants/coaltar.pdf).

Jayasinghe DM (1975). Bhaysha Kalpana Paribhashava: in Ayurveda Pharmacophoea, vol. 1. Department of Ayurveda, Sri Lanka, Colombo, Sri Lanka. p. 30.

L'Hostis M, Seegers H (2002). Tick-borne parasitic diseases in cattle: current knowledge and prospective risk analysis related to the ongoing evolution in French cattle farming systems. Vet. Res. 33:599-611.

Linklater A, Angus KW, Mitchell B, Spence JA, Rowland AC, Hunter AR (1982). Pneumonia in sheep associated with dipping in carbolic dips. Vet. Rec. 110:33-36.

Malesela JS (2004). Assessing implementation of veterinary Extension on control of cattle parasites, in Moretele District, North West Province, South Africa. (unpublished Thesis, University of Pretoria).

Marufu MC, Chimonyo M, Dzama K, Mapiye C (2010). Seroprevalence of tick-borne diseases in communal cattle reared on sweet and sour rangelands in a semi-arid area of South Africa. Vet. J. 184(1):71-76.

Masika PJ, Sonandi A, van Averbeke W (1997). Tick control by smallscale cattle farmers in the central Eastern Cape Province, South Africa. J. S. Afr. Vet. Assoc. 68:45-48.

Mbati PA, Hlatshwayo M, Mtshali MS, Mogaswane KR, deWaal TD, Dipeolu OO (2002). Tick and tick borne diseases of livestock belonging to resource poor farmers in the Eastern Free State of South Africa. Springer Netherlands. 28:217-224.

Moyo B, Masika PJ (2009). Tick control methods used by resourcelimited farmers and the effect of ticks on cattle in rural areas of the Eastern Cape Province, South Africa. Trop. Anim. Health Prod. 41:517-523.

Moyo B, Masika PJ, Dube S, Maphosa V (2009). An in-vivo study of the efficacy and safety of ethno-veterinary remedies used to contro cattle ticks by rural farmers in the Eastern Cape Province of South Africa. Trop. Anim. Health Prod. 41:1569-1576.

Mwale M, Bhebhe E, Chimonyo M, Halimani TE (2005). Use of herbal plants in poultry health management in the Mushagashe small-scale commercial farming area in Zimbabwe, Int. J. Appl. Res. Vet. Med. 3:163-170.

Nchu F, Magano SR, Eloff JN (2012). In vitro anti-tick properties of the essential oil of Tagetes minuta L. (Asteraceae) on Hyalomma rufipes (Acari: Ixodidae). Onderstepoort J. Vet. Res. 79(1):E1-5.
Njoroge GN, Bussmann RW (2006). Herbal usage and informant consensus in ethnoveterinary management of cattle diseases among the kikuyus (Central Kenya). J. Ethnopharmacol. 108:332-339.

Okello-Onen J, Kerwegi SA, Olila D, Ssekitto CCMB, Osinde C (2004). Participatory Evaluation and Improvement of ethno-veterinary practices for tick control in Lango and Teso Farming System. Final technical report.

Okello-Onen J, Rutagwenda T (1997). A Study on the status of East coast-fever, causes of calf mortality and abortion in Ankole cattle in ankole ranching scheme, Mbarara District, Uganda. Final Report, GTZ project, Sanga, Mbarara. p. 36.

Pamo TE, Tendonkeng F, Kana JR, Payne VK, Boukila B, Lemoufouet J, Miegoue E, Nanda AS (2005). A study of the acaricidal properties of an essential oil extracted from the leaves of Ageratum houstonianum. Vet. Parasitol. 125:319-323.

Panella NA, Dolan MC, Karchesy JJ, Xiong Y, Peralta-Cruz J, Khasawneh M, Montenier JA, Maupin GO (2005). Use of novel compounds for pest control, Insecticidal and Acaricidal activity of Essential Oil Components from Heartwood of Alaska Yellow Cedar. J. Med. Entomol. 42:352-358.

Pirali-Kheirabadi K, Razzaghi-Abyaneh M (2007). Biological activities of chamomile (Matricaria chamomile) flowers's extract against the survival and egg laying of the cattle fever tick (Acari Ixodidae) $\mathrm{J}$. Zhejiang Univ. Sci. B. 8:693-696.

Pontes WJT, de Oliveira Jose CS, Camara Claudio AG, Lopes Adelmo CHR (2007). Composition and acaricide Activity of Resin's Essential Oil of Protium batianum daly against two spotted spider mite (Tetranychus urticae): JEOR.(http:// findarticles.com/p/articles/im_qa4091/is_200707/ai_n 19434104).

Sarin RC (2004). Insecticidal activity of callus culture of Tagetes erecta, Fitoterapia 75:62-64.

Seyoun A, Kabirru EW, Lwande W, Killen DF, Hassanali A, Knols BG (2002). Repellency of live potted plants against Anopheles gambiae from human baits in semi-field experimental huts. Am. J. Trop. Med. Hyg. 67:191-195.

Statistical Analyses System (SAS) (2003). Statistical analysis system user's guide (5 th Edition), version 6, (SAS Institute Inc., Raleigh, North carolina, USA).

Swan G (2001). Index of veterinary specialities, Vol. 38. No. 3, September- November 2000.

Thorsell W, Mikiver A, Tunon H (2005). Repelling properties of some plants materials on the tick Ixodes ricinus L. Phytomedicine 13:132 134.

Tomova BS, Waterhouse JS, Doberski J (2005). The effect of fractionated Tagetes oil volatiles on aphid reproduction Entomol. Experimentalis. et Applicata 115:153-159. 